\title{
O impacto da avaliação da economia no apoio à democracia
}

\author{
Vitor de Moraes Peixoto \\ Jéssica Matheus de Souza
}

\begin{abstract}
RESUMO: O artigo discute como a avaliação sociotrópica da economia e a mobilidade social se relacionam com o nível de adesão à democracia ou a formas autoritárias de governo, no ciclo 2006-2016. Conclui-se que avaliar bem a economia do país e perceber mobilidade social ascendente tende a levar os indivíduos a declarar mais apoio incondicional ao sistema democrático e demostrar graus de insatisfação menores com a democracia. Além disso, esses indivíduos tendem a apoiar menos golpes militares em cenários com alta criminalidade.
\end{abstract}

PALAVRAS-CHAVE: Atitudes Democráticas. Apoio à democracia. Mobilidade Social. Avaliação da Economia.

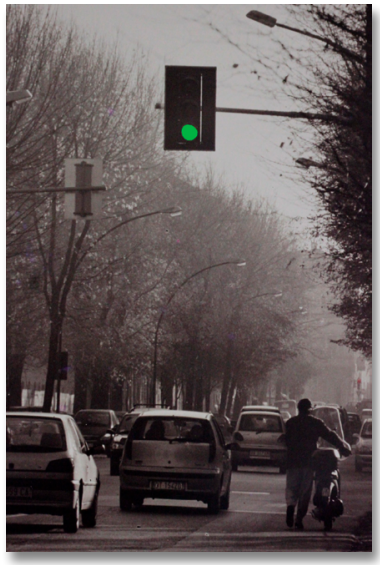

\section{The impact of economic assessment on support for democracy}

\section{Vitor de Moraes Peixoto \\ Professor associado da Universidade Estadual do Norte Fluminense Darcy Ribeiro. \\ E-mail: moraespeixoto@gmail.com}

\section{$\overline{\text { Jéssica Matheus de Souza }}$}

Mestranda em Sociologia Política da Universidade Estadual do Norte Fluminense Darcy Ribeiro.

E-mail: jessicamatheus@outlook.com
ABSTRACT: The article discussed how sociotropic evaluation of the economy and social mobility relate to the level of adherence to democracy or to authoritarian forms of government, during the 2006-2017 cycle. The results showed that assessing the country's economy well and perceiving upward social mobility tends to lead individuals to declare more unconditional support for the democratic system and to show lesser degrees of dissatisfaction. In addition, these individuals tend to support fewer military coups in high crime scenarios.

KEYWORDS: Democratic Attitudes. Support for democracy. Social Mobility. Economy Evaluation.

RECEBIDO: 07/08/2019

APROVADO: 07/01/2020 


\section{Introdução}

O artigo objetiva realizar análises acerca da avaliação da economia nacional e da mobilidade social, bem como de seus impactos sobre um conjunto de atitudes e comportamentos individuais conhecidos por apoio à democracia dos últimos quatro ciclos eleitorais. Por meio de análises dos dados de survey do Latin American Public Opinion Project (LAPOP), propõe-se a entender como a avaliação sociotrópica da economia se relaciona com o nível de adesão à democracia ou a formas autoritárias de governo, tendo como parâmetro a opinião pública brasileira no ciclo 2006 - 2016.

Explora-se o mecanismo causal através do qual classe social e avaliação de governo afetam as atitudes em relação ao apoio ao sistema democrático. A pergunta de pesquisa aqui utilizada para explorar essa problemática pode ser traduzida da seguinte forma: como visões sobre a economia do país e sobre a própria mobilidade social se refletem na maior ou menor propensão do indivíduo apoiar o sistema democrático?

A hipótese é que uma boa avaliação da economia do país e uma percepção de mobilidade social ascendente tendam a levar os indivíduos a declarar mais apoio e satisfação em relação ao sistema democrático, enquanto um cenário em que a situação econômica nacional e pessoal é percebida como pior levaria indivíduos a responsabilizar a democracia, mostrando menos apoio e satisfação. A segunda hipótese implica que avaliações egotrópicas e sociotrópicas da economia também afetariam o apoio a medidas autoritárias de governo, em específico à concordância com golpe miliar quando há exacerbado índice de crime ou corrupção e fechamento do Congresso. Uma piora econômica levaria, nesse caso, o indivíduo a defender medidas autoritárias por acreditar que seriam soluções para melhorar a economia do país e também sua própria condição.

A questão perpassa o tema das transformações sociais, principalmente a mudança valorativa e cultural que se associa a uma maior propensão de instauração ou adesão à democracia (INGLEHART; WELZEL, 2009). Assim, a primeira parte do artigo consiste na revisão da literatura, que traz dimensões especificas da política brasileira, aproveitando a expansão dos estudos 
nacionais sobre atitudes e comportamento eleitoral. Foram consolidadas, nos últimos anos, redes de pesquisa e análise de dados de questionários de dois grandes empreendimentos: os Estudos Eleitorais Brasileiros (ESEB) e o Latin American Public Opinion Project (LAPOP). ESEB e LAPOP juntos favoreceram estudos sobre a evolução do partidarismo no Brasil; o voto partidário e o impacto da avaliação econômica sobre o voto (VEIGA, 2011; DE SOUZA CARREIRÃO, 2002; NICOLAU 2014); a mobilidade social e o voto (PEIXOTO; RENNÓ, 2011); a informação e o voto (VEIGA, 2002); e, principalmente, a cultura e a participação política (BORBA, 2005; RIBEIRO; BORBA, 2010; RIBEIRO; DE SOUZA CARREIRÃO; BORBA, 2011 é realizada uma análise descritiva geral da evolução dos sentimentos partidários dos eleitores entre 2002 e 2010, utilizando dados dos ESEB (Estudos Eleitorais Brasileiros; FUKS, 2016).

Os resultados foram divididos em três seções: a primeira consta da construção da variável independente de mobilidade social e a avaliação sociotrópica da economia. A segunda seção se trata de operacionalizar as variáveis de apoio ao sistema democrático, assim relacionando as variáveis confiança nas eleições, preferência pela democracia e satisfação com o funcionamento do sistema democrático com as duas variáveis independentes. Por fim, a terceira seção apresenta a relação entre apoio a formas autoritárias de governo e mobilidade social ou avaliação da economia do país. Encerra-se com a construção de modelos logísticos no intuito de estimar as razões de chances de um indivíduo ser favorável ao fechamento do Congresso e apoiar golpes militares quando há crime e corrupção.

\section{Teoria da modernização e surgimento dos valores pós- modernos}

A base teórica aqui decantada tem como foco a versão revisitada da teoria da modernização apresentada por Inglehart e Welzel (2005), segundo a qual o desenvolvimento socioeconômico daria vez a um conjunto de valores pós-materialistas, provocando profundas alterações no campo religioso, no mundo do trabalho, nas relações de gênero, nas normas sexuais e na atividade 
política. Essa mudança de valores promove pressões cada vez maiores para o estabelecimento da democracia, em países de regime autoritário, ou aprofundamento dela, em países em fase de consolidação do regime democrático.

Os autores relatam uma mudança cultural que nasce da modernização socioeconômica, uma mudança emancipatória trazendo novos padrões valorativos, uma vez que antigos valores estão mudando em direção previsível em medida que o desenvolvimento socioeconômico ocorre. O novo conjunto de valores tem importantes consequências em relação à forma com que as sociedades são governadas, na medida em que a mudança cultural estimula uma demanda por maior igualdade de gênero, liberdade democrática e boa governança. Os valores de massa desempenham papel fundamental no surgimento de instituições democráticas.

Para Inglehart (2012) a mudança de valores nas sociedades pós-industriais se fundamenta na hipótese que os indivíduos perseguem vários objetivos em ordem hierárquica, o que justifica a máxima atenção às necessidades consideradas mais importantes. O exemplo do autor é a necessidade fundamental por alimento, que, uma vez saciada e garantida, dá lugar a um desejo de segurança econômica, e depois que essa foi conquistada, passa a ser meta a aquisição de bens mundanos como símbolos de afluência.

Em sua análise sobre a mudança de valores da população na Europa Inglehart destaca o fator intergeracional que consta nas condições materiais de criação das gerações, que passa do estágio de priorização das necessidades materiais básicas a outro patamar. As populações das sociedades ocidentais, segundo ele, ultrapassaram este estágio e foram socializadas em um período de afluência sem precedentes, tomando agora a segurança econômica como garantida.

A teoria apresentada por Inglehart e Welzel (2005) considera o impacto do desenvolvimento socioeconômico e a resistência da herança cultural de uma sociedade, afirmando uma mudança sociocultural não linear. Após a industrialização, que causou racionalização secularização e burocratização, ocorre a ascensão da sociedade do conhecimento, que coloca outro conjunto de valores, suscitando ênfase cada vez maior na autonomia individual, 
livre escolha e auto-expressão. Os valores emergentes dão origem a um processo de desenvolvimento humano que caminha em direção a uma sociedade humanística, que preza pela emancipação humana.

Assim, as sociedades mais pobres tendem a assumir valores focados na sobrevivência material, as sociedades de nível intermediário, nas quais as pessoas dispõem de maior segurança existencial, estão centradas na capacidade de realização individual e, por fim, as sociedades ricas, no exercício da imaginação, tolerância, valores ecológicos, livre escolha, bem-estar e valores de auto-expressão. Dessa forma, o processo de modernização socioeconômica estimula a formação de novos padrões valorativos, promovendo uma mudança emancipatória de valores, com a emergência dos valores cívicos, liberais e de auto-expressão.

[...] uma cultura humanística - que enfatiza valores de auto-expressão - propaga-se por todos os grandes domínios da vida, ajudando a dar uma nova forma a normas sexuais, papeis de gênero, valores familiares, religiosidade, motivações para o trabalho, relação das pessoas com a natureza e com o meio ambiente, e suas atividades comunitárias e participação politica. A crescente valorização da autonomia humana é evidente em todos esses domínios, transformando o tecido das sociedades contemporâneas. [...] Papéis de gênero, orientações religiosas, padrões de consumo habito de trabalho e comportamento eleitoral se tornam, cada vez mais, questões de escolha individual (INGLEHART; WELZEL, 2005, p. 20).

A modernização socioeconômica gera as capacidades objetivas que possibilitam a escolha autônoma para cada vez mais pessoas, e os valores de autoexpressão levam que elas exijam liberdade de escolha, a qual é permitida pelos direitos assegurados por instituições democráticas. Essa mudança de valores promove pressões cada vez maiores para o estabelecimento da democracia.

De acordo com os autores, os valores de autoexpressão não necessitam de um regime democrático prévio pra aflorar, podendo surgir em regime autoritário, causando assim uma demanda em massa por um regime democrático, ou uma democracia mais 
eficiente, no caso de regimes democráticos de baixa qualidade. A respeito da herança cultural, os autores afirmam que embora os valores possam mudar, eles continuam a refletir a herança histórica de uma sociedade; a mudança cultural é dependente da trajetória.

A teoria da modernização é elaborada no contexto das nações pós-industriais. Por isso, é cabível o estudo da aplicabilidade de seus conceitos e previsões nos casos de jovens democracias com problemas materiais e econômicas pendentes, como o caso brasileiro. Assim, existe a indagação sobre a transposição do modelo de Inglehart e Welzel para países latino-americanos.

São analisados a seguir trabalhos acerca da percepção da democracia entre os brasileiros tanto em seu caráter normativo quanto no seu funcionamento prático, a mobilidade social como fator de impacto na cultura e opinião pública, bem como a temática do pensamento autoritário e a possibilidade de sobrevivência de valores autoritários que se originaram durante a ditadura militar.

\section{Mobilidade social e atitudes políticas}

Rennó e Turgeon (2016) têm como foco o fenômeno da mobilidade social e seus desdobramentos nas atitudes políticas da população brasileira, abordando as diferentes hipóteses levantadas pela literatura especializada e testando-as utilizando os dados do Barômetro das Américas do ano de 2012. Os autores partem de uma revisão da literatura que abarca classes sociais e psicologia política para discorrer sobre as possíveis diferenças comportamentais entre diferentes classes sociais, envolvendo também padrões de mobilidade social. A literatura nacional aponta as implicações políticas do surgimento de uma nova classe média no Brasil, que traria mudanças na percepção política e social da população. A literatura internacional coloca as classes intermediárias e a camada em ascensão como potencializadores da moderação de conflitos sociais e tolerância. Destarte, esses setores são associados a uma postura mais aberta, tolerante e moderada. 
Foram operacionalizados os dados considerando os conceitos de classe social, mobilidade, não-opiniões, extremismo de atitudes, heterogeneidade atitudinal e tolerância. O critério utilizado para definir a colocação dos indivíduos nas categorias foi a mensuração de classe social com base em bens. Dividiu-se a população nas classes: baixa, média baixa, média e alta. A ascensão social foi medida através de duas perguntas que questionavam se o entrevistado mudou de classe de 2004 até a data da entrevista e a qual classe pertencia antes.

Os resultados apresentaram evidências que a não-opinião diminui conforme a situação socioeconômica dos indivíduos passa para camadas mais privilegiadas. Os membros da classe média baixa expressaram menos não-opiniões que os da classe baixa, os da classe média menos que os da classe média-baixa, e os membros da classe média exibiram menos não-opiniões que a classe alta vezes sim, vezes não, mostrando pouca diferença entre elas nesse quesito. Assim, a não-opinião na classe média e alta foram sempre inferiores aos outros grupos e raramente significativas. Concluiu-se que a classe média se assemelha mais à classe alta que as mais baixas, e ao contrário do esperado, não apresenta mais opiniões indefinidas que as demais, prevalecendo a tese que os ganhos de acesso à informação decorrentes de uma melhora socioeconômica têm impacto na formação de opinião de forma linear. Os resultados quanto aos outros conceitos analisados não mostraram grandes diferenças entre as classes sociais e grupos de mobilidade social, tampouco apontaram as qualidades que seriam específicas aos setores intermediários ou aos grupos que apresentaram ascensão social. Concluiu-se que as classes médias compartilham visões de mundo com a classe alta, e ambas se diferenciam da classe baixa.

\section{Adesão à democracia no Brasil}

Ribeiro (2008) averiguou a existência de associação entre priorização de metas pós-materialistas e ocorrência de valores e atitudes favoráveis à instauração ou aprofundamento de regimes democráticos utilizando o caso brasileiro, que se distingue das 
nações pós-industriais para as quais a teoria do desenvolvimento humano foi originalmente formulada.

Utilizando dados do projeto World Values Survey (WVS), verificou-se que indivíduos pós-materialistas no cenário nacional também tendem a manifestar valores mais democráticos. Um ponto de divergência teórica em relação a Inglehart e Welzel é ressaltado pelo autor:

Contribuindo significativamente para o debate sobre a relevância de fatores subjetivos para o funcionamento de sistemas políticos, através do emprego de uma série de indicadores que servem de medidas de democracia para mais de cinquenta sociedades, incluindo o Brasil, esses autores [Inglehart e Welzel] sustentam a tese de que os valores no nível individual estão fortemente conectados às instituições democráticas. Identificar essa ligação, entretanto, é apenas parte do problema quando se trata de analisar o relacionamento entre cultura e instituições. Apesar de acreditarmos que a posição mais prudente e plausível sobre o tema seja considerar a existência de uma mútua determinação dos componentes culturais e institucionais nos processos de democratização, a polêmica acerca desse assunto continua (RIBEIRO, 2008, p. 105).

Além disso, Ribeiro chama a atenção para os resultados da coleta de dados realizada no Brasil no ano de 1997, os quais mostram que a taxa de concordância (em parte ou totalmente) com a afirmação "a democracia pode ter problemas, mas é melhor do que qualquer outra forma de governo", que se colocou na época em 83\%. Esse dado foi utilizado mundialmente como indicador de adesão à democracia, mostrando que o país acompanhou as tendências globais acerca do apoio ao regime. O autor menciona também o Instituto Latinobarômetro, que desde 2002 realiza o acompanhamento dessa variável, e indicou uma tendência de elevação nos níveis de adesão normativa na América Latina.

Apesar disso, outro achado significativo foi a verificação que $60 \%$ dos entrevistados brasileiros, ainda segundo os dados do WVS, consideram boa ou ótima a situação em que um líder forte ocupa o centro do poder sem preocupar-se com o Congresso. Isso 
denota que a adesão abstrata ao ideal democrático no Brasil não é acompanhada de rejeição da alternativa autoritária, o que pode ser alarmante principalmente quando há no país um contexto de crise econômica e/ou política.

Com intuito de analisar as orientações dos cidadãos brasileiros a respeito da democracia e instituições democráticas, Moisés (2008) examina como a população brasileira participou do processo de transição do regime autoritário para o democrático. Essa mudança é colocada como gradual, e não brusca ou definitiva, sendo assim pertinente questionar a adesão dos brasileiros ao regime democrático como um ideal e como sistema prático, a fim de verificar a sobrevivência de atitudes autoritárias que possam comprometer a aceitação do regime. Para Moisés, a preferência de parte dos brasileiros por soluções à margem da lei e da democracia para a resolução de problemas sociais está associada com o descrédito em elementos constituintes da democracia, como partidos políticos e parlamento. O autor aponta a incongruência entre a adesão normativa ao regime e o julgamento da democracy-in-action; indicando que o desempenho dos governos e das instituições não está assegurando que as expectativas dos cidadãos possam ser atendidas.

Relacionando a teoria da modernização ao contexto da América Latina, Ribeiro e Borba (2010) examinaram a associação entre os valores pós-materialistas e uma postura participativa, a qual é proposta pelos defensores da teoria do desenvolvimento humano, notadamente, o trabalho de Inglehart e Welzel (2005). Testando a nível individual e de grupo de quatro países latino-americanos (Argentina, Brasil, Chile e Peru) se as mudanças valorativas e as orientações subjetivas seriam acompanhadas de uma postura crítica a respeito do funcionamento das instituições políticas e mecanismos tradicionais de participação. Os resultados obtidos apontaram que nessas populações a participação tem mais influência de variáveis ligadas à centralidade social dos cidadãos que de mudanças nas prioridades valorativas. Assim, foi concluído que a transposição do modelo explicativo de Inglehart para países latino-americanos é problemática, devendo ser considerada de maneira crítica. 
Fuks, Casalecchi, Gonçalves e David (FUCKS et al, 2016) avançaram no entendimento da natureza problemática da adesão à democracia no Brasil e tratam o problema a partir de uma visão multidimensional, resgatando os componentes que encontram maior consenso na literatura como indispensáveis à democracia. Dessa forma, direcionaram o foco para os aspectos atitudinais do regime democrático, ou seja, a forma pela qual os cidadãos se relacionam com ele. Seu trabalho buscou testar o quão democráticos são os democratas brasileiros. Desse modo, mediram a adesão à democracia por meio do apoio aos valores próprios da democracia, além da própria declaração de preferência por esse regime. Os resultados mostraram que os brasileiros que dizem aderir à democracia não manifestam a mesma intensidade de adesão às suas dimensões principais. Os aspectos voto e participação política contaram com forte apoio, enquanto os procedimentos de escolha e representação política se mostraram com adesão mais frágil. Concluiu-se que mesmo os democratas, o público que supostamente teria atitudes mais democráticas, não manifesta apoio às diversas dimensões democráticas de forma consensual. Todavia, os democratas brasileiros apresentaram atitudes mais democráticas que democratas de outros países latino-americanos, com níveis próximos aos dos norte-americanos.

Quanto aos fenômenos do antipatidarismo e do apartidarismo, cuja discussão é pertinente ao trabalho, ganharam relevância nos últimos anos não só no cenário nacional, como também no internacional. Achados de Gimenes (2017) chamam a atenção para um afastamento do eleitorado com relação aos partidos, discussão que estuda os possíveis efeitos de um desalinhamento dos regimes democráticos. Foi ressaltado que são escassos e pouco conclusivos os estudos em democracias em processo de consolidação, como boa parte dos países da América Latina. Dessa forma, o autor afirma que modelos teóricos desenvolvidos no âmbito das democracias consolidadas como Estados Unidos e países da Europa Ocidental não devem ser imediatamente transpostos ao contexto dos países que são novos ao regime. O autor analisou como o antipartidarismo se observa na fração dos eleitores que não mostra simpatia partidária. Os apartidários cognitivos são os 
eleitores com maior mobilização cognitiva, que se diferem dos que são definidos como independentes apolíticos, grupo que se caracteriza por menor mobilização cognitiva. A parcela que mostra preferência por uma legenda divide-se em partidários cognitivos e partidários rituais, sendo que os últimos são a parcela com baixa mobilidade cognitiva. Segundo o autor, o apartidário cognitivo, grupo que corresponde a cerca de 10\% dos eleitores latino-americanos, poder ser considerado o perfil de eleitor mais próximo às exigências normativas da democracia; isso acontece porque, se tratando de correlatos atitudinais e comportamentais, há sinais de maior informação, ter maior sentimento de eficácia política, aderir ao regime democrático em maior medida, participando mais, tanto em termos eleitorais quanto contestatoriamente.

Gimenes aponta que a baixa adesão aos partidos se justifica ao menos parcialmente com a maior proporção do novo tipo de eleitor, os apartidários cognitivos, que são os eleitores que não expressam partidarismo e possuem maior mobilização cognitiva, aos quais julga como um perfil de cidadão que contribui à democracia. O apartidário cognitivo, grupo que corresponde a cerca de $10 \%$ dos eleitores latino-americanos, poder ser considerado o perfil de eleitor mais próximo às exigências normativas da democracia; isso acontece porque, se tratando de correlatos atitudinais e comportamentais, há sinais de maior informação, ter maior sentimento de eficácia política, aderir ao regime democrático em maior medida, participando mais, tanto em termos eleitorais quanto contestatoriamente.

Além disso, Ribeiro, Fuks e Borba (2018) realizaram uma investigação a respeito dos tipos de antipartidarismo presentes no Brasil e as diferenças entre eles quanto aos desdobramentos atitudinais e comportamentais. Os autores distinguem o antipartidarismo moderado do antipartidarismo extremo, já que o último apresenta o elemento da intolerância política. O antipartidarismo moderado tem sido mais discutido na literatura política, tem como medida a rejeição aos partidos e é um bom preditor de votos. Já o antipartidarismo extremo ainda é um tema insipiente e é caracterizado por intolerância, gerando uma situação do tipo "nós contra eles", que faz com que certos grupos partidários se tornem alvos 
se sentimentos de intolerância. O trabalho distingue quatro tipos de antipartidarismo: ativo (um grupo partidário como alvo, não intolerante), passivo (dois grupos partidários como alvo, não intolerante), polarizado (um grupo partidário como alvo, intolerante) e generalizado (dois grupos partidários como alvo, intolerante). O antipartidarismo antissistema é aquele que tem como alvo todos os grupos partidários e apresenta intolerância a todos eles. Esse tipo de antipartidarismo conduz à mobilização política e a atitudes antidemocráticas. O artigo comprova a hipótese que o antipartidário generalizado apoia menos a democracia.

Outro importante destaque na literatura, vários aspectos culturais são investigados a fim de entender se e como podem interferir na manutenção e qualidade do regime democrático. Aferir posições políticas, conhecimento sobre as instituições, avaliação de agentes e resultados é atividade frequente registrada por múltiplos surveys, porém dificultada ou impossibilitada em países e períodos de regime autoritário, acarretando um gap no conhecimento da área. Respostas aos pontos anteriores são interpretadas como sinais de estabilidade democrática. Para Przeworski, Cheibub e Limongi (2003) permanece aberta a questão de se saber se essas respostas são capazes de predizer se a democracia sobreviverá ou não.

A proposta presente neste trabalho não é pertencente a essa última linha de discussão, uma vez que aqui será estudado o impacto da situação econômica na opinião pública, e não dessas duas variáveis quanto à manutenção do sistema democrático.

Não obstante os grandes avanços da literatura para explicar variáveis atitudinais e comportamentais em relação à adesão aos valores democráticos, salvo melhor juízo, ainda não foram testadas o poder explicativo da mobilidade social e avaliações sociotrópicas sobre apoio às instituições democráticas. Destarte, este artigo se propõe exatamente a construir modelos explicativos tendo como variáveis dependentes as justificativas de golpes militares e fechamento do Congresso e, como variáveis independentes, a percepção de mobilidade social e avaliação sociotrópica da economia. 


\section{Construção das variáveis independentes: percepção de mobilidade social e avaliação sociotrópica da economia}

A construção da variável mobilidade social levou em consideração duas perguntas do questionário LAPOP. A primeira questão indagava o entrevistado acerca da classe social em que ele se localizava há oito anos estimulada em cinco opções: classe baixa, classe média baixa, classe média, classe média alta e classe alta. Em seguida, a pergunta solicitava que o indivíduo se auto localizasse nestas mesmas opções, porém, atualmente.

Ao realizar o cruzamento entre estas duas variáveis foi possível identificar três categorias de indivíduos: os que declararam pertencer à mesma classe, portanto, apresentaram imobilidade, que representam 45\% dos respondentes em 2017; os que ascenderam, ou seja, aqueles que afirmaram pertencer a uma classe superior àquela de 8 anos atrás, que somaram cerca de 27,8\% dos entrevistados; e finalmente aqueles que declararam que hoje pertencem a uma classe inferior, que são os $26,9 \%$ que descenderam socialmente.

Cabe notar que nas edições das rodadas anteriores do LAPOP estas questões eram precedidas por uma pergunta filtro que indagava o entrevistado sobre se ele percebia que havia mudado de classe, sem, no entanto, oferecer as opções. Este procedimento teve potencial para que as respostas tenham sido afetadas pelo fato dos indivíduos não identificarem exatamente o que o entrevistador concebe por classe social, colocando a possibilidade de responder que não notaram mudança de classe antes de afirmar a qual classe pertencem atualmente.

Quanto à avalição sociotrópica, se destaca o brusco crescimento da porcentagem de pessoas que passam a afirmar que a economia piorou a partir de 2012, saindo de $20 \%$ naquele ano para ultrapassar 70\% em 2016.

\section{Variáveis atitudinais de apoio à democracia}

Para operacionalizar as variáveis de apoio ao sistema democrático foi utilizado um conjunto de três variáveis atitudinais referente à satisfação e apoio ao sistema democrático, assim como confiança nas eleições. 
Sobre o nível de confiança nas eleições, foi indagado aos entrevistados numa escala de 1 a 7 , onde 1 significa nenhuma confiança e 7 total confiança, como se sentiam em relação às eleições no Brasil. Os resultados são muito estarrecedores: mais de um terço não tem confiança alguma nas eleições, e a nota zero chega a alcançar $38,8 \%$ entre os que perceberam mobilidade descendente. A confiança total nas eleições não chega a $7 \%$ entre os que perceberam mobilidade ascendente e desce a $4,2 \%$ entre os descendentes.

Ao analisar a confiança nas eleições pela avaliação sociotrópica da economia as diferenças tornam-se mais salientes. É possível afirmar que é duas vezes mais provável encontrar um indivíduo que não tem confiança nenhuma nas eleições entre os que avaliam que a economia do país piorou do que entre os que acreditam que melhorou. Na outra ponta, total confiança nas eleições, o inverso também pode ser afirmado: 13,5\% entre os que avaliam a melhora da economia, enquanto apenas $6 \%$ dos que acreditaram que a economia havia piorado confiam totalmente nas eleições.

\section{Gráfico 1: Percentagem de confiança dos entrevistados nas eleições}

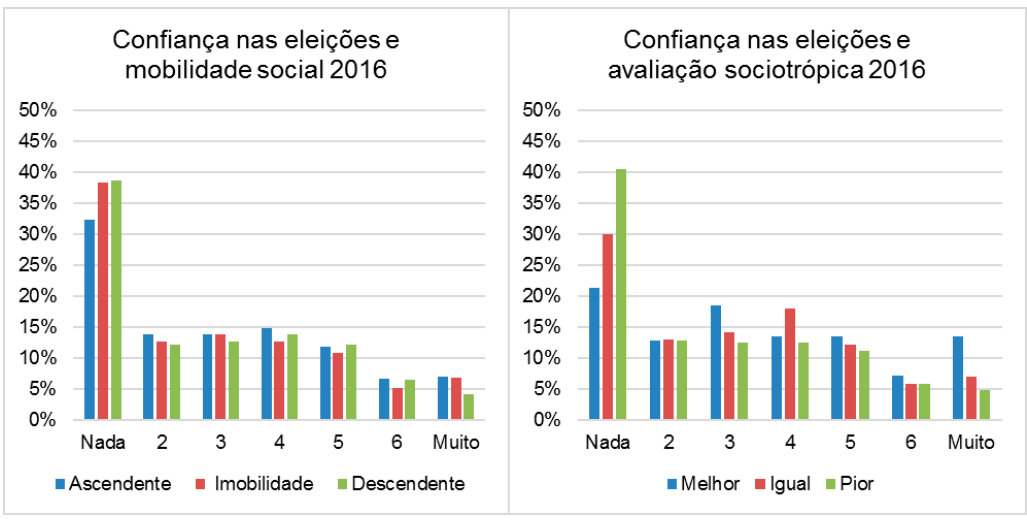

Fonte: Elaborado pelos autores.

No que concerne ao suporte à forma democrática de governo, foi indagado sobre a concordância/discordância com a afirmação de que a democracia é a melhor forma de governo a despeito dos seus problemas. Os achados empíricos confirmam os resultados 
anteriores aqui demonstrados, que tanto a mobilidade social percebida quanto a avaliação da economia sociotrópica impactam nos extremos da avaliação de concordância/discordância com a afirmação da democracia ser a melhor forma de governo. Entretanto, a avaliação da economia tem um impacto mais marcante do que a mobilidade nos extremos da escala de confiança, chega a atingir quase duas vezes mais confiança total se comparar as categorias de que acreditam que a economia melhorou (34\% de concordância total) com aqueles que acreditam que a economia piorou $(17,9 \%$ de concordância total).

\section{Gráfico 2: Opinião dos entrevistados sobre a democracia ser a melhor forma de governo para o Brasil}

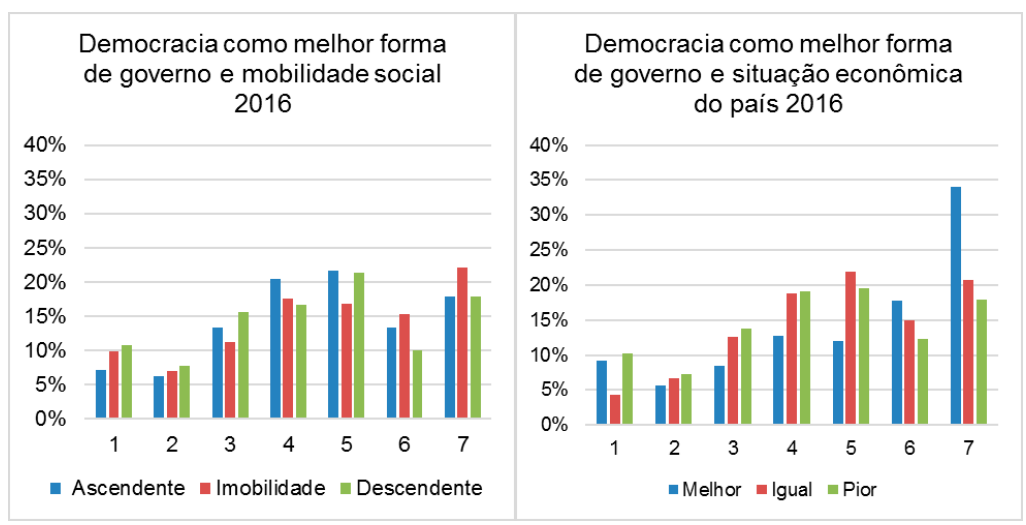

Fonte: Elaborado pelos autores.

Outra forma de operacionalizar as atitudes em relação com a democracia foi por meio da indagação acerca da satisfação com o funcionamento do sistema democrático. A pergunta indagava os entrevistados da seguinte forma: "De uma maneira geral, o sr. está muito satisfeito, satisfeito, insatisfeito ou muito insatisfeito com o funcionamento da democracia no Brasil?".

O gráfico 3 chama a atenção para concentração de respondentes insatisfeitos e muito insatisfeitos com o regime democrático, que alcança $76 \%$ da população. Não há diferenças fortes entre avaliações egotrópicas e sociotrópicas quanto aos que estão satisfeitos com o regime, porém a relação muda completamente no que 
concerne ao grau de insatisfação. Na avaliação egotrópica, a diferença entre indivíduos de mobilidade ascendente e descendente que se mostraram muito insatisfeitos foi de 11 pontos percentuais, ou seja, 21,5\% dos ascendentes está muito insatisfeito, contra $32,2 \%$ dos descendentes. No quesito avaliação da economia do país a disparidade foi ainda maior, saindo de 13,4\% de muita insatisfação com a democracia entre pessoas que avaliaram a economia como melhor, para 29,3\% ente os indivíduos que classificaram como pior.

\section{Gráfico 3: Satisfação dos entrevistados com a democracia brasileira}

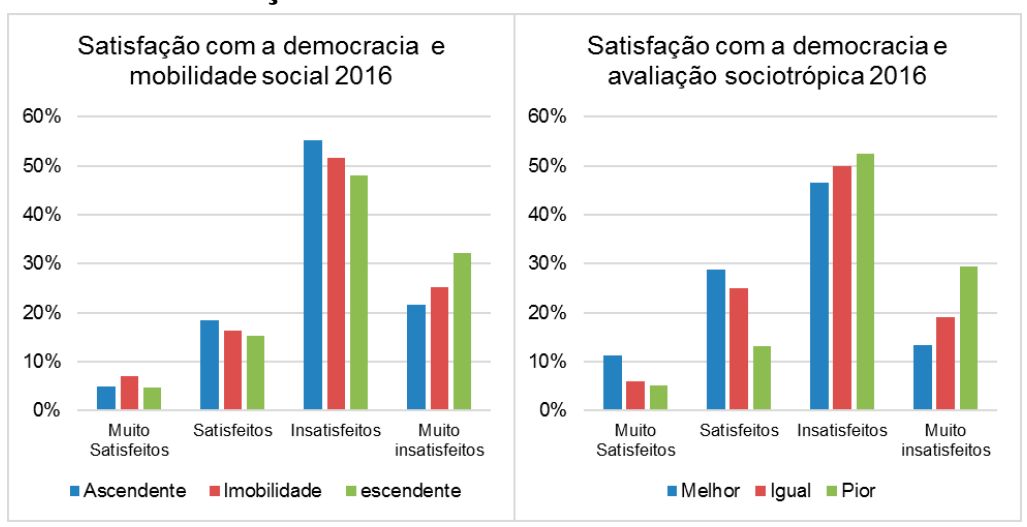

Fonte: Elaborado pelos autores.

\section{Apoio a modelos autoritários}

Outro objetivo foi entender a relação entre apoio a formas autoritárias de governo com as variáveis independentes. Foram analisadas três situações de acordo com as perguntas encontradas no questionário LAPOP. Na primeira situação, os entrevistados eram perguntados se um golpe militar seria justificável quando há muito crime; na segunda, se justificaria quando há muita corrupção; e na terceira, se era aceitável que o presidente feche o Congresso e governe sem ele caso o país esteja enfrentando dificuldades.

$\mathrm{Na}$ análise longitudinal, foi possível estimar a porcentagem de indivíduos que foi a favor de golpe militar quando há muito crime, do golpe quando há muita corrupção e de o presidente governar 
sem o Congresso, no decorrer dos anos analisados. Enquanto o apoio ao fechamento do Congresso não mostrou grande variação, ficando entre $15 \%$ e $20 \%$, a concordância com o golpe quando há crime teve seu ápice em 46,6\% em 2008, e o consentimento a golpe justificado por corrupção foi de 47,6 em 2014. Ambos os últimos tiveram variação entre 34 e $48 \%$ ao longo do período.

Assim, em 2016, 37,5\% dos entrevistados foram a favor de golpe quando há muito crime e 34,7\% quando há corrupção; 19,5\% foram a favor que o presidente governe sem o Congresso. Foi estimada a porcentagem de indivíduos que foram a favor de cada rompimento democrático entre os que ficaram imóveis, acenderam ou descenderam socialmente. A discrepância que mais se destaca é que entre aqueles que ascenderam socialmente, 33\% foram a favor do golpe em caso de alta criminalidade, em comparação a $44 \%$ que foram a favor entre os que descenderam.

Fora as variáveis independentes avaliação egotrópica e avaliação sociotrópica da economia, foram utilizadas também outras para aferir a existência de relação com as variáveis dependentes: apoio ao golpe e fechamento do Congresso. As variáveis e as possíveis relações esperadas são:

- Sexo: mulheres tenderiam a rechaçar mais medidas autoritárias;

- Religião: pessoas católicas, protestantes tradicionais, evangélicos pentecostal influenciariam a apoiar medidas autoritárias.

- Anos de estudo; renda mensal habitacional: era esperado que acarretassem em menor atração por medidas autoritárias.

- Idade: quanto maior a idade, menor seria a propensão para golpe.

- Carência de refeição; vítima de crime; insatisfação com a vida; desemprego: era esperado que presentes esses fatores gerassem responsabilização do sistema democrático pela situação social, acarretando propensão a adesão a medidas autoritárias.

- Antipetismo e antipessedebismo: a presença de antipartidarismo poderia estar positivamente relacionada a atitudes antidemocráticas. 
- $\quad$ Macrorregião nacional; posicionamento político à direita ou esquerda: foram analisados sem expectativas discrepância quanto a adesão a golpes ou fechamento do congresso.

A tabela a seguir mostra a razão de chances para fechamento do Congresso e apoio a golpes miliares quando há crime e corrupção, de acordo com as variáveis analisadas.

Tabela 1 - Chances para fechamento do Congresso no Brasil, de acordo com diferentes grupos sociais

\begin{tabular}{|c|c|c|c|c|c|c|}
\hline \multirow{2}{*}{$\begin{array}{c}\text { Variáveis na } \\
\text { equação }\end{array}$} & \multicolumn{2}{|c|}{ Crime } & \multicolumn{2}{|c|}{ Corrupção } & \multicolumn{2}{|c|}{$\begin{array}{c}\text { Fechamento do } \\
\text { Congresso }\end{array}$} \\
\hline & Sig. & $\operatorname{Exp}(B)$ & Sig. & $\operatorname{Exp}(B)$ & Sig. & $\operatorname{Exp}(B)$ \\
\hline Mulher & .017 & .702 & .431 & .887 & .068 & .769 \\
\hline Católico & .834 & 1.055 & .460 & 1.222 & .286 & 1.320 \\
\hline $\begin{array}{l}\text { Protestante } \\
\text { tradicional }\end{array}$ & .770 & 1.098 & .205 & 1.521 & .889 & 1.048 \\
\hline $\begin{array}{l}\text { Evangelico } \\
\text { pentecostal }\end{array}$ & .412 & 1.254 & .522 & 1.209 & .471 & 1.228 \\
\hline Sem religião & .277 & .648 & .893 & 1.053 & .524 & 1.260 \\
\hline Anti petista & .003 & 1.632 & .840 & 1.035 & .625 & .926 \\
\hline Anti pessedebista & .034 & .702 & .255 & 1.216 & .530 & .904 \\
\hline Esquerda & .328 & 1.186 & .472 & .883 & .836 & 1.036 \\
\hline Direita & .276 & 1.226 & .311 & .824 & .036 & 1.450 \\
\hline $\begin{array}{l}\text { Mobilidade } \\
\text { ascendente }\end{array}$ & .835 & 1.038 & .904 & .979 & .725 & .942 \\
\hline $\begin{array}{l}\text { Mobilidade } \\
\text { descendente }\end{array}$ & .028 & 1.451 & .628 & .916 & .835 & .966 \\
\hline Escolaridade & .716 & .992 & .087 & .962 & .130 & .969 \\
\hline Idade & .104 & 1.008 & .373 & 1.005 & .013 & 1.012 \\
\hline Socio_melhor & .617 & 1.167 & .386 & 1.302 & .687 & 1.124 \\
\hline Socio_pior & .051 & 1.508 & .290 & 1.247 & .174 & 1.307 \\
\hline Vitima & .940 & 1.013 & .971 & 1.006 & .894 & 1.022 \\
\hline Insatisf_vida & .516 & 1.184 & .208 & 1.383 & .881 & 1.039 \\
\hline Des empregado & .889 & .941 & .259 & 1.557 & .181 & 1.667 \\
\hline Renda Familiar & .625 & .992 & .987 & 1.000 & .008 & .955 \\
\hline Constante & .000 & .099 & .000 & .155 & .000 & .183 \\
\hline
\end{tabular}

Fonte: Elaborado pelos autores. 
Na tabela acima as variáveis antipetismo e antipessedebismo foram construídas a partir de uma questão incluída no questionário LAPOP em 2016 que objetivava identificar qual o grupo de desafeição dos entrevistados.

A pergunta se formula: "falando de alguns grupos de pessoas, poderia informar o quanto gosta ou desgosta dos listados abaixo. Usaremos agora uma escala de 1 a 10, na qual 1 significa 'desgosto muito' e 10 significa 'gosto muito'". As colocadas são "pessoas que defendem a legalização do aborto", "pessoas que defendem o regime militar", "comunistas", "petistas" (simpatizantes do PT) e "PSDBistas" (simpatizantes do PSDB). Nesse trabalho as notas de 1 a 3 atribuídas aos petistas e PSDBistas, entram na classificação de antipetismo e antipessedebismo, respectivamente.

No modelo para apoio a golpe militar quando há muito crime, foram significativas e positivas as variáveis antipetista e mobilidade descendente, e negativas as variáveis mulher e antipessedebista. Assim, as chances de um indivíduo apoiar golpe quando há muito crime aumentam caso ele seja antipetista ou tenha abaixado de classe social, e diminuem caso seja mulher ou antipessedebista. No modelo para apoio a golpe militar quando há muita corrupção não foram encontrados resultados estatisticamente significativos.

Finalmente, no modelo para justificativa ao fechamento do congresso para que o presidente governe sozinho, foi significativa e positiva a variável ser de direita e idade, e negativas as variáveis renda e sexo feminino. Dessa forma, ser mulher ou ter maior renda acarreta em menos chance do indivíduo apoiar o fechamento do Congresso, e o contrário acontece com pessoas de direita e de maior idade.

\section{Conclusões}

Neste artigo foram exploradas duas dimensões atitudinais: a primeira em relação ao apoio e à satisfação com o sistema democrático e a segunda concernente a justificativas de golpes militares.

No quesito apoio à democracia, as variáveis de mobilidade de classe e avaliação sociotrópica da economia demonstraram estar relacionadas com os extremos das escalas. Ou seja, avaliar bem a 
economia do país e perceber mobilidade social ascendente tende a levar os indivíduos a declarar mais apoio incondicional ao sistema democrático e igualmente se mostrarem com graus de insatisfação menores. Assim, a hipótese principal do estudo foi comprovada.

Ao se analisar as justificativas para golpes, três foram as situações: golpe militar em situações de muito crime, onde se percebeu que tanto a mobilidade social quanto a avaliação sociotrópica tiveram covariação negativa, ou seja, indivíduos com percepção de mobilidade ascendente e avaliação positiva da economia tendem a apoiar menos golpes militares em caso de crime. No entanto, pouco ou nenhuma significância estatística nos golpes em casos de corrupção ou mesmo fechamento do Congresso.

Golpes militares em caso de crime e fechamento do Congresso foram rechaçados mais por mulheres do que por homens com coeficientes estatisticamente significativos. Os indivíduos que se declaram de direita são mais propensos a apoiar o fechamento do Congresso, assim como os antipetistas são mais inclinados a golpes militares em situações de muito crime.

Esses resultados apontam que as percepções sobre economia e mobilidade social impactam o apoio ao sistema democrático, principalmente, as avaliações sociotrópicas da economia, que interferiram significativamente nos níveis confiança nas eleições, a satisfação com a democracia e a preferência pela forma democrática de governo. Os resultados representam avanço no conhecimento acerca do funcionamento da democracia no Brasil uma vez que vão além da concepção que a economia impacta no voto ou na avaliação presidencial, na direção que até mesmo o sistema democrático pode ser responsabilizado por resultados econômicos insatisfatórios.

Assim, os dados conduzem à percepção da fragilidade do apoio ao sistema democrático. Esse apoio é relevante uma vez que significaria que as pessoas valorizam a democracia em si mesma, mesmo que os resultados que ela possa gerar sejam discrepantes com sua opinião pessoal. Todavia, os resultados desse artigo apontaram que para muitos brasileiros a democracia não seria um sistema desejável por si só, sua desejabilidade dependeria dos resultados que entrega. Isso é problemático uma vez que um país 
inserido em um sistema econômico global pode sofrer interferência de fatores exógenos que abalem sua economia, o que viria a prejudicar a satisfação da população com o sistema democrático.

A literatura recente já abarcou exemplos de fatores que interferem na esconomia de um país e fogem do controle do governo. Campello e Zucco (2016) afirmam que os países sul-americanos se inserem na economia mundial de forma semelhante: são exportadores de produtos primários, possuem baixa poupança interna e por isso são dependentes de financiamento externo. Assim, são extremamente vulneráveis a flutuações nos preços internacionais das commodities, que exercem impacto direto em suas taxas de crescimento. Outro fator de impacto são variações nas taxas de juros internacionais. Esses fatores contribuem para oscilações entre ciclo de bonanças e crise na região, o que impacta o bem-estar social e gera instabilidade política. Com isso, o contexto histórico e econômico da região e os ciclos voláteis da economia são determinados em geral por fatores externos, e não por obra de governantes. Por consequência, o voto de responsabilização por meio do qual o eleitor julga o presidente pelo desempenho da economia seria fundado em aspectos que o líder do executivo não controle sobre.

Como foi visto, a literatura também aponta problemas referentes a adesão ao sistema democrático. Carrillo (2020) afirma que mesmo que a democracia ainda seja a preferência majoritária na região, se trata de uma maioria pouco robusta. Além dos democratas, existe um segmento da população é indiferente a tipo de regime e outro, menor, prefere a alternativa autoritária. Houve aumento significativo da parcela da população que se mostra indiferente no período de 2013 a 2017. Soma-se a isso o achado de Fuks, Casalecchi e Ribeiro (2019), que colocam que por mais que a maioria dos latino-americanos afirmem que a democracia é preferível a qualquer forma de governo, o apoio aos princípios democráticos se dá de forma desigual. Alguns desses princípios contam com grande aprovação, como apoio a eleições livres e competitivas e independência dos poderes, e outros com baixo apoio, como o estado de direito, a participação em manifestações pacíficas e a tolerância política. Os democratas coesos, ou seja, que aderem 
a todos os princípios democráticos, estão em pequeno número, apenas 12,8\% dos latino-americanos em 2010.

Quanto a problemática dos fatores que podem interferir no apoio à democracia, Moisés e Carneiro (2008) apontam que o apoio a democracia no Brasil diminui com o aumento da desconfiança dos cidadãos em instituições públicas e a diminuição com a satisfação com o regime. As atitudes de desconfiança e insatisfação com a democracia aumentam a chance de os entrevistados escolherem desenhos institucionais que excluem os partidos políticos e o Congresso Nacional, ou seja preferirem alternativas anti-institucionais atribuindo pouca ou nenhuma importância aos partidos políticos e parlamento.

Destarte, o apoio a democracia não parece ocorrer por uma preferência desse tipo de governo baseada somente em seus princípios, estão envolvidos fatores contextuais que podem estar ligados ao funcionamento das instituições públicas ou ou podem estar fora de controle, como os fatores economicos mencionados. Além disso, caso explicações culturalistas se mostrarem corretas e a cultura política de fato for importante para a manutenção do sistema democrático, o problema posto é ainda mais grave. Com o apoio à democracia refém da avaliação da economia, fatores exógenos possam vir a interferir na economia podem abalar o funcionamento democrático de uma nação.

\section{REFERÊNCIAS}

BORBA, J. Cultura política, ideologia e comportamento eleitoral: alguns apontamentos teóricos sobre o caso brasileiro. Opinião pública, Campinas, v. 11, n. 1, p. 147 - 168, 2005.

CAMPELLO, D.; ZUCCO JR, C. Presidential success and the world economy. The Journal of Politics, v. 78, n. 2, p. 589 - 602, 2016.

DE SOUZA CARREIRÃO, Y. A decisão do voto nas eleições presidenciais brasileiras. Campinas: FGV Editora, 2002.

FUKS, M.; CASALECCHI, G. A.; RIBEIRO, E. A. Determinantes contextuais da coesão do sistema de crenças democrático: evidências a partir da América Latina. Revista Brasileira de Ciência Política, Brasília, n. 28, p. 7 - 32, 2019. 
FUKS, M. et al. Qualificando a adesão à democracia: quão democráticos são os democratas brasileiros? Revista Brasileira de Ciência Política, Brasília, n. 19, p. 199 - 219, 2016.

GIMENES, E. R. Eleitores E Partidos Políticos Na América Latina. Curitiba: Appris, 2017.

INGLEHART, R. A revolução silenciosa na Europa: mudança intergeracional nas sociedades pós-industriais. Revista de Sociologia e Política, Curitiba, v. 20, n. 43, p. 159 - 191, 2012.

INGLEHART, R.; WELZEL, C. Modernização, mudança cultural e democracia: a sequência do desenvolvimento humano. São Paulo: Francis, 2009.

MOISÉS, J. A. Cultura Política, Instituições e Democracia - lições da experiência brasileira. Revista Brasileira de Ciências Sociais, São Paulo, v. 23, n. 66, p.11 - 44, 2008.

MOISÉS, J. A.; CARNEIRO, G. P. Democracia, desconfiança política e insatisfação com o regime: o caso do Brasil. Opinião Pública, Campinas, v. 14, n. 1, p. $1-42,2008$.

MONSIVAIS-CARRILLO, A. La indiferencia hacia la democracia en América Latina. Íconos: Revista de Ciencias Sociales, n. 66, p. 151 - 171, 2020.

NICOLAU, J. Determinantes do voto no primeiro turno das eleições presidenciais brasileiras de 2010: uma análise exploratória. Opinião Pública, Campinas, v. 20, n. 3, p. 311 - 325, 2014.

PEIXOTO, V.; RENNÓ, L. Mobilidade social ascendente e voto: as eleições presidenciais de 2010 no Brasil. Opinião Pública, Campinas, v. 17, n. 2, p. $304-332,2011$.

PRZEWORSKI, A.; CHEIBUB, J. A.; LIMONGI, F. Democracia e cultura: uma visão não culturalista. Lua Nova, n. 58, p. 9 - 35, 2003.

RENNÓ, L.; TURGEON, M. A Psicologia Política das Classes Sociais no Brasil: Atributos das Atitudes Políticas por Estratificação e Mobilidade Social. Dados: Revista de Ciências Sociais, Brasília, v. 59, n. 1, p. 11 - 51, 2016.

RIBEIRO, E. A. Valores pós-materialistas e adesão normativa à democracia entre os brasileiros. Revista Debates, Porto Alegre, v. 2, n. 2, p. 103 - 133, 2008.

RIBEIRO, E. A.; BORBA, J. Participação e pós-materialismo na América Latina. Opinião Pública, Campinas, v. 16, n. 1, p. $28-64,2010$. 
RIBEIRO, E.; DE SOUZA CARREIRÃO, Y.; BORBA, J. Sentimentos partidários e atitudes políticas entre os brasileiros. Opinião Pública, Campinas, v. 17, n. 2 , p. $333-368,2011$.

RIBEIRO, E.; FUKS, M.; BORBA, J. Antipartidarismo e intolerância política no Brasil. In: Encontro Anual da Associação Nacional de Pós-graduação e Pesquisa em Ciências Sociais (ANPOCS), 43., Caxambu, 2018. Anais... Caxambu, 2018. Disponível em: <https://anpocs.com/index.php/ encontros/papers/42-encontro-anual-da-anpocs/gt-31/gt05-29>. Acesso em: 05 mar. 2020.

SCANLON, T. M. A dificuldade da tolerância. Novos Estudos - CEBRAP, n. 84, p. $31-45,2009$.

VEIGA, L. F. O partidarismo no Brasil (2002/2010). Opinião Pública, Campinas, v. 17, n. 2, p. $400-425,2011$.

Os partidos brasileiros na perspectiva dos eleitores: mudanças e continuidades na identificação partidária e na avaliação das principais legendas após 2002. Opinião pública, Campinas, v. 13, n. 2, p. $340-365$, 2007. 